\title{
Nature and extent of counseling practice in community pharmacies in Sulaimani city, Iraq: A cross-sectional study
}

\begin{tabular}{cc}
\hline Khanda Taifwr Hamasalih $^{1 *}$ & Walid Hassan Nitham $^{2}$ \\
\hline Abstract &
\end{tabular}

Background and objective: Community pharmacists play an important role in the best use of drugs and in improving patient outcomes. Evidence demonstrates that pharmacists' counseling improves the quality of life, clinical outcomes, and drug and disease knowledge and reduces the utilization of health services. This study aimed to investigate the nature and extent of counseling practices of community pharmacists in community pharmacies in Sulaimani region of Kurdistan, Iraq.

Methods: A cross-sectional survey was conducted in community pharmacies in Sulaimani city, in a one-month duration from November to December 2020. The sample size was 100 community pharmacies, which were selected randomly. The data were stored and analyzed using Excel 2016 and expressed as frequencies and percentages.

Results: According to the completed questionnaires, about $78.8 \%$ of pharmacists would do counseling spontaneously each time they dispense any drug. Only $61 \%$ of the pharmacists would ask the patients if they understood what was said during their communication to assess the understanding of advice given to their patients. The most common barrier observed during patient counseling was the patient's lack of time.

Conclusion: This study indicates that community pharmacists counsel the patients in an appropriate way. They provide information orally and in written form. However, further research is needed to evaluate the quality of patient counseling by using different methods like pseudo-patient methodology to gain real counseling data.

Keywords: Counselling; Community pharmacist; Community pharmacy; Counselling barriers.

\section{Introduction}

In community settings, pharmacy staffs' counseling plays a key role in ensuring the quality use of medications. ${ }^{1}$ Community pharmacists play an important role in optimizing drug use and improving patient outcomes. At the same time, they have the ability to prevent medication misuse and reduce drug costs. ${ }^{2}$ Counseling is one of the essential services in community pharmacy, for both over the counter (OTC) and prescription-only medicines. ${ }^{3}$ Patient counseling usually occurs while dispensing prescriptions but may also be provided as a separate service. ${ }^{4}$ A systematic review findings indicate that counseling in community pharmacies improves clinical outcomes, $^{5}$ quality of life and patients' satisfaction with health services. ${ }^{6}$ At the time of dispensing, community pharmacists' counseling encourages appropriate medication use and prevents drug related problems. ${ }^{7,8}$ All of the following information is required during counseling: name of the medicine, indications, dose and dosage form, route of drug administration, directions for use, duration of therapy, side effects, precautions, and contraindications. ${ }^{9}$ Pharmacy professionals provide proper counseling at pharmacies which needs their involvement to give suitable, understandable, and appropriate information about patients' medication. ${ }^{10}$

${ }^{1}$ Department of Clinical Pharmacy, College of Pharmacy, University of Sulaimani, Sulaimani, I raq

2 Shar Hospital, Sulaimani Directorate of Health, Sulaimani, I raq.

* Correspondence: khanda.hamasalih@univsul.edu.iq 
The aim is to increase drug knowledge and create awareness of the patients on proper adherence. Therefore, pharmacists must be sure that the information is provided in clear language and check whether or not patients have understood it by letting them repeat it in their own words. ${ }^{11}$

Pharmacists play a crucial role in counseling self-medicated consumers. They monitor the use of OTC, identify drug-related problems, and if the patients use their drugs safely, effectively, and appropriately. $^{7}$ Poor counseling can increase the risk of drug administration errors, drug overdose, harm, or even death. ${ }^{12}$ In Kurdistan, community pharmacists are often the only point of contact for patients before initiating drug therapy, not only for OTC medication but also for prescription-only medicines (POM). This study aimed to investigate the extent and nature of counseling practice of community pharmacists in Sulaimani city during drug dispensing.

\section{Methods}

The study utilized a cross-sectional survey to assess the extent and nature of patient counseling in community pharmacies. The selection of 100 pharmacies from the initial list was conducted using a simple random sampling. A face-to-face questionnaire composed of 10 multiple choices was designed. One form was completed for every pharmacy. Each of the pharmacists was responsible for the accurate completion of the questionnaire. They were allowed to choose one or more than one choice while answering the questions. The questionnaires were structured in such a way to allow getting outcomes based on the study objectives. They included a question of the identity of the pharmacy and measurement of the current nature and extent of counseling.

Assessing the nature of counseling included the questions to figure out how often pharmacists counsel their patients, what kind of information they give them, and what other instructions they mention on each patient visit.

Assessing the extent of counseling implicated measuring the methods that have been used for patient counseling such as verbal or written advice and how pharmacist would assess the understanding of the patient.

The evaluation of factors that may influence counseling was achieved by rating the importance of communication barriers related to pharmacists and patients.

\section{Data analysis}

Data were entered and checked by one of the authors. They were stored and analyzed using Excel 2016 and expressed as frequencies and percentages.

\section{Ethical approval}

The study was reviewed and approved by the ethical committee of the College of Pharmacy, University of Sulaimani, and the head of Sulaimani pharmacists' syndicate. All participants were notified that their responses and private demographic information were kept confidential.

\section{Results}

A total of 99 completed questionnaire were received by the researchers, which was composed of ten multiple choices. Only one pharmacist did not want to complete the survey. Approximately 50 of the participants were male, and 49 were female, as shown in Table 1.

Eighty-two pharmacies were located in the non-crowded area, while 17 of them were located in a crowded area, as shown in Table 2.

According to Table 3, just one pharmacist was working in $57.6 \%$ of the pharmacies, while more than one pharmacist was working in $42.4 \%$ of the pharmacies.

As shown in Table 4, pharmacists were responsible for dispensing medicinal products in $48.5 \%$ of the pharmacies.

Table 5 demonstrated that $78.8 \%$ of pharmacists would do counseling spontaneously each time they dispense any drug. About $20.2 \%$ of pharmacists would do it only for prescribed drugs 
and $10 \%$ only when the patient seeks information. Ninety five percent of the respondents were using both written and verbal advice during counseling, but $3 \%$ of them were just using written information on the packet of the drug, only $2 \%$ of them were using just verbal advice.

Table 1 Pharmacy staff of different gender groups (male and female)

\begin{tabular}{lcc}
\hline Providers & No. & $\%$ \\
\hline Female & 49 & $49.5 \%$ \\
Male & 50 & $50.5 \%$ \\
Total & 99 & $100 \%$ \\
\hline
\end{tabular}

Table 2 Location of the community pharmacies according to crowdedness

\begin{tabular}{lcc}
\hline Location of the pharmacies & No. & $\%$ \\
\hline Non-crowded & 82 & $82.8 \%$ \\
Crowded & 17 & $17.2 \%$ \\
Total & 99 & $100 \%$ \\
\hline
\end{tabular}

Table 3 Number of pharmacists working in a pharmacy

\begin{tabular}{lcc}
\hline How many pharmacists works in your pharmacy? & No. & $\%$ \\
\hline One & 57 & $57.6 \%$ \\
More than one & 42 & $42.4 \%$ \\
None & 0 & $00.0 \%$ \\
Total & 99 & $100 \%$ \\
\hline
\end{tabular}

Table 4 The person responsible for counseling patients in the pharmacy

\begin{tabular}{lcc}
\hline Who is responsible for counseling patients in the pharmacy? & No. & $\%$ \\
\hline Pharmacist & 48 & $48.5 \%$ \\
Pharmacist assistant & 3 & $3 \%$ \\
Both of them & 48 & $48.5 \%$ \\
Total & 99 & $100 \%$ \\
\hline
\end{tabular}

Table 5 Frequency with which pharmacists expect to counsel patients in their pharmacy

\begin{tabular}{lcc}
\hline How often do you give counselling to your patient? & No. & $\%$ \\
\hline Spontaneously each time I dispense any drug & 78 & $78.8 \%$ \\
Only for prescribed drugs & 20 & $20.2 \%$ \\
When if the patient seeks information & 1 & $1.0 \%$ \\
Total & 99 & $100 \%$ \\
\hline
\end{tabular}


Table 6 illustrates the assessment of patient understanding and satisfaction with verbal advice. Most counselors would ask the patients if they understood what was said.

Table 7 summarizes the type and extent of drug information the pharmacists used to give their patients; it was allowed for the pharmacists to choose more than one choice. It appears that the focus was on how to take medicines and the worst on what to do if the medicine is lost or spoiled. The impact was graded by the percentage, as shown in Table 8.

The important counseling barriers were patients in a hurry, pharmacists' lack of time, and patients already knowing information about their medication.

Table 6 Assessment of patient understanding and satisfaction with verbal advice

\begin{tabular}{lcc}
\hline & No. & $\%$ \\
\hline How do you assess patient understanding of the advice? & & \\
I question them & 17 & $17.2 \%$ \\
I ask them if they understood my counseling & 61 & $61.6 \%$ \\
I ask them to relate the information back to me & 21 & $21.2 \%$ \\
How do you assess patients' satisfaction? & 62 & $62.6 \%$ \\
I ask them & 2 & $2.0 \%$ \\
I run surveys & 8 & $8.1 \%$ \\
I have a feedback box in the pharmacy & 27 & $27.3 \%$ \\
None of the above & 99 & $100 \%$ \\
Total & & \\
\hline
\end{tabular}

Table 7 Type and extent of information related to the use of medications

\begin{tabular}{lcc}
\hline Information about the use of medications & No. & \% (n=99) \\
\hline 1. How to take the medication & 92 & $92.9 \%$ \\
2. How long should the medication be taken & 69 & $69.7 \%$ \\
3. How should the medication be stored & 64 & $64.6 \%$ \\
4. Why the medication should be taken in the whole course & 41 & $41.4 \%$ \\
5. What is the maximal dose & 39 & $39.4 \%$ \\
6. In what case to consult the doctor or the pharmacist before a next appointment & 31 & $31.3 \%$ \\
7. When not to take the medication & 35 & $35.4 \%$ \\
8. What to do with the unused medicine at the end of the treatment & 25 & $25.3 \%$ \\
9. What to do if the medicine is lost or spoiled & 17 & $17.2 \%$ \\
\hline
\end{tabular}

Table 8 Frequency distribution of barriers on counseling performance

\begin{tabular}{lcc}
\hline Type of barrier & No. & \% (n=99) \\
\hline -Pharmacist-lack of time & 35 & $35.4 \%$ \\
-Pharmacist-lack of staff & 28 & $28.3 \%$ \\
-Pharmacist-distractions such as noise, phone call, etc. & 16 & $16.2 \%$ \\
-Pharmacist-lack of experience with patient counselling & 6 & $6 \%$ \\
-Patients are in a hurry & 56 & $56.7 \%$ \\
-Patients request not to be counseled because they already know about & 35 & $35.4 \%$ \\
the medication & 21 & $21.2 \%$ \\
-Patients have hearing or language problems & 19 & $19.2 \%$ \\
-Patients have elderly related cognitive problems & &
\end{tabular}




\section{Discussion}

In practical settings, patients do not generally achieve information about the benefits and risks of their treatment, so that $30 \%$ to $50 \%$ of the patients do not use their medications as prescribed. ${ }^{13}$ This study showed that supplemental written information and verbal advice are not always given, but most of the time in about $95 \%$ of cases. Both of the methods, written and verbal advice, are crucial since sometimes the leaflet is not in the box, or even it is not understandable by the patient. Therefore, the pharmacist must provide oral and written information and mostly focus on verbal to create a good relationship with their patients.

In the present study, pharmacists appeared to have sufficient knowledge about patient counseling, and they found themselves important sources of information for patients. According to Tucker et al., even if doctors and nurses instruct patients on the correct use of drugs, pharmacists support this message and help patients remember and understand it. ${ }^{14}$ Our results showed that $78.8 \%$ of the respondents counsel the patient directly each time they dispense drugs. The majority of the pharmacists always provide information about the dosage of the drug, proper use of medication, how to deal with side effects, and encourage them to take their drugs appropriately to help patients achieve the desired therapeutic outcome.

In our present study, the main factors that affected counseling achievement were mostly patients' lack of time, pharmacists' lack of time, and patients who do not like to be counseled because they already know about the medication. Statistic trends showed patient-in hurry overweighing pharmacist-lack of time $(56.7 \%$ versus $35.4 \%)$. According to Latif et al., the most common barriers observed included lack of education and privacy, the impatient behavior of patients, the time constraints of pharmacists, and gender differences. ${ }^{15}$ While in another study, the most common barriers during counseling were patients' lack of time and lack of interest. ${ }^{16}$ Therefore, continuous professional development and pharmacists' involvement in special training programs like medication counseling programs can improve pharmacists' knowledge and pharmacistpatient counseling skills. ${ }^{17}$

Finally, the main strategy to overcome counseling barriers such as lack of patient's interest and time is to promote public education regarding their medical conditions. This might improve patients' communication skills by changing their mindset. Moreover, another common solution to overcome the barriers is increasing the number of community pharmacists, as lack of time was one of the major problems faced by most pharmacists.

This study may not generalize the data for all community pharmacists in Sulaimani as only selected pharmacies were included. Hence, the findings may not reflect the perception of the entire community pharmacists in Sulaimani.

\section{Conclusion}

This study indicated that community pharmacists' counseling was appropriate. They provided information orally and in a written form. However, some barriers negatively affected counseling, including patients' lack of time, pharmacists' lack of time, and patients who do not like to be counseled because they already know about the medication. Further research is needed to evaluate the quality of patient counseling using different methods like pseudo-patient methodology to gain real counseling data.

\section{Funding}

None.

\section{Competing interests}

None declared.

\section{References}

1. Grace S, Adji P, Yosi I, Eko S, Bruce S. Counselling practices in an East Javan district, Indonesia: what information is commonly 
gathered by pharmacy staff? J Pharm Health Serv Res. 2021; 12(2):254-61. https://doi.org/10.1093/ iphsr/rmab001.

2. Nkansah N, Mostovetsky O, Yu C, Chheng T, Beney J, Bond $\mathrm{CM}$, et al. Effect of outpatient pharmacists' non-dispensing roles on patient outcomes and prescribing patterns. Cochrane Database Syst Rev. 2010; 7:CD000336. https://doi.org/10.1002/14651858.CD000336. pub2.

3. Hassan Q, Tahani A, Ayidh M, Abdullah A. Community pharmacist counselling practices in the Bisha health directorate, Saudi Arabia simulated patient visits. BMC Health Serv Res. 2020; 20:745. https://doi.org/10.1186/s12913-02005554-2.

4. Sinaa A, Norah O. Counselling practices in community pharmacies in Riyadh, Saudi Arabia: a cross-sectional study. BMC Health Serv Res. 2015; 15:557. https://doi.org/10.1186/s12913-0151220-6.

5. Maes KA, Ruppanner JA, Imfeld-Isenegger TL, Hersberger KE, Lampert ML, Boeni $F$. Dispensing of prescribed medicines in Swiss counseling activities. Pharmacy (Basel). 2019; 7:1. https://doi.org/10.3390/pharmacy7010001.

6. Okumura LM, Rotta I, Correr CJ. Assessment of pharmacist-led patient counseling in randomized controlled trials: a systematic review. Int J Clin Pharm. 2014; 36:882-91. https://doi.org/10.1007/ s11096-014-9982-1.

7. Eickhoff C, Hämmerlein A, Griese N, Schulz M. Nature and frequency of drug-related problems in self-medication (over-the-counter drugs) in daily community pharmacy practice in Germany. Pharmacoepidemiol Drug Saf. 2012; 21(3):25460. https://doi.org/10.1002/pds.2241.

8. Nicolas A, Eickhoff C, Griese N, Schulz M. Drug-related problems in prescribed medicines in Germany at the time of dispensing. Int J Clin Pharm. 2013; 35(3):476-82. https://doi.org/ 10.1007/s11096-013-9769-9.

9. Nasir T, Raju NJ, Mulugeta T. Knowledge, attitude and practice of patient medication counseling among drug dispensers in North West Ethiopia. J Appl Pharm Sci. 2011; 01(07):85-90.

10. Ayalew $M$. Medication counseling practice in Ethiopia: A systematic review. J Basic Clin Pharm. 2017; 8:S001-5.

11. FMHACA US. Manual for Medicines Good Dispensing Practice. 2nd ed. Ethiopia: FMHACA; 2012. P.15

12. Alfadl AA, Alrasheedy AA, Alhassun MS. Evaluation of medication counseling practice at community pharmacies in Qassim region, Saudi Arabia. Saudi Pharm J. 2018; 26:258-62. https://doi.org/10.1016/j. jsps.2017.12.002.

13. Muaed A. community pharmacy prescription screening in the UAE. Pharmacol Pharm. 2014; (5):83-91. https://doi.org/10.4236/pp.2014.51013.
14. Tucker R. Community pharmacists' perceptions of the skin conditions they encounter and how they view their role in dermatological care. Int J Pharm Pract. 2012; 20(5):344-6. https://doi.org/10.1111/j.2042-7174.2012.00212.x.

15. Latif, F, Ahmad R, Naqvi A, Ahmad N. Pharmacist perceived barriers to patient counseling: A study in Eastern Region of Saudi Arabia. J Pharm Res Int. 2017; 19(6):1-12. https://doi.org/10.9734/JPRI/2017/37705.

16. Rajiah K, Kaur K, Sivarasa S, Yeow M. Perception of community pharmacists towards patient counseling and continuing pharmacy education program in Kuala Lumpur and Selangor states of Malaysia. Am J Pharm Health Res. 2014; 2(1).48-56. https://doi.org/10.1016/ j.phclin.2015.08.005.

17. Hager DR, Hartkopf $K$, Margolis A, Martin BA. Pharmacist behavior changes following a medication counseling training program targeting teach-back and plain language. Innov Pharm. 2016; 7(1):8. https://doi.org/10.24926/iip.v7i1.418. 